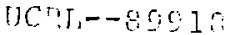

\section{DESt 001763}

CYTOMETRY OF MAMMALIAN SPERM

Barton L. Gledhil!

BIOMEDICAL SCIENCES DIVISION

This paper was prepared for submittal to U.S. DOE R eproductive Toxicology Workshop 12-14 October 1983

University of California, San Francisco

October 11,1983

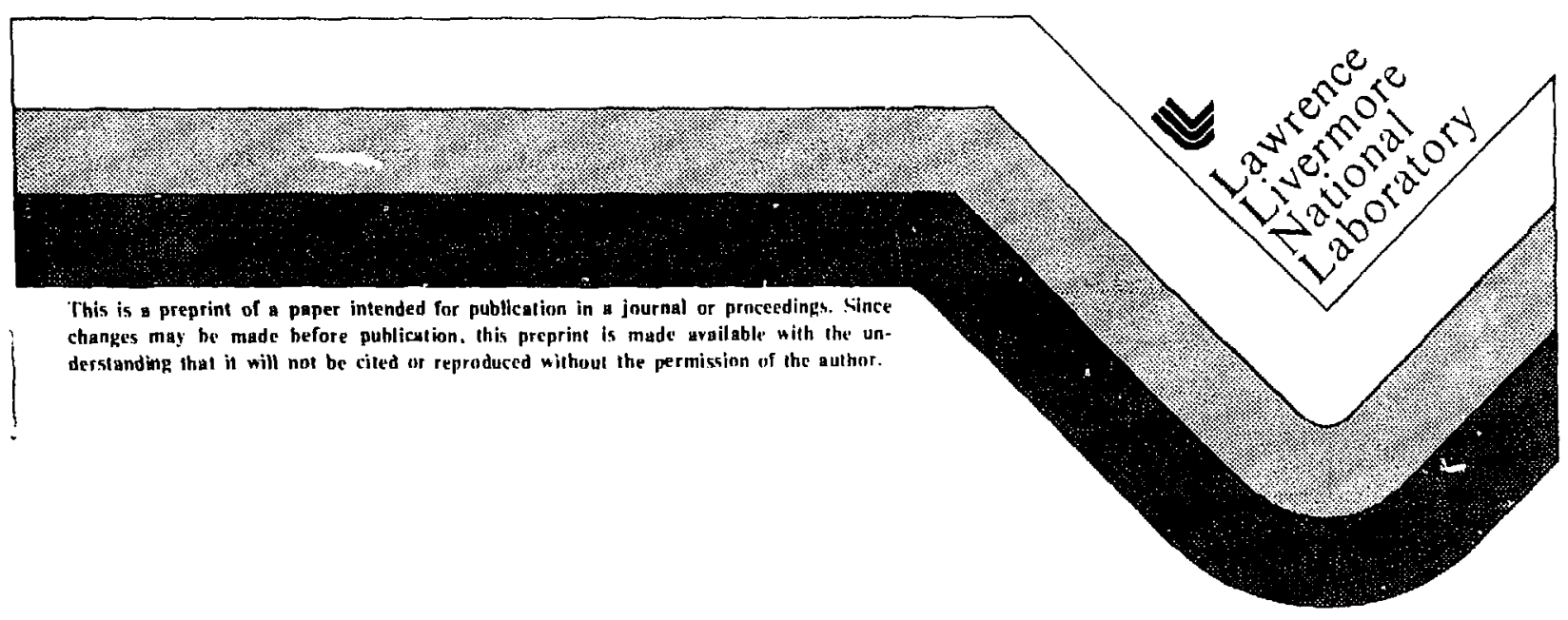




\title{
CYTOMETRY OF MAMMALIAN SPERM
}

\author{
Barton L. Gledhill \\ Lawrence Livermore National Laboratory \\ Biomedical Sciences Division \\ University of California \\ P.O. Box 5507 L-452 \\ Livermore, California 94550
}

\section{DISCLAIMER}

\begin{abstract}
This report was prepared as an account of woik sponsored by an agency of the United States Government. Neither the United States Government nor any agency thereof, nor any of their employes, makes any warranty, express or implied, or assumes any legal liability or responsibility for the accuracy, completeness, or usefulness of any infor nation, apparatus, product, or process disclosed, or represents that its use would not infringe privately owned rights. Reference herein to any specific commercial product, process, or service by trade name. trademark, manufacturer, or otherwise does not necessarily constitute or imply its endorsement, recommendation, or favoring by the United States Government or any agency thereof. The views and opinions of authors expressed herein do not necessarily state or reflect those of the United States Government or any agency thereof.
\end{abstract}

Work performed under the auspices of the U.S. Department of Energy by the Lawrence Livermore National Laboratory under contract number W-7405-ENG-48. 
Concern over reproductive toxins in the environment has created a need for methods of testing for induced testicular damage. Sperm can serve as a biological dosimeter of induced alteration. The frequency of sperm with ma!formed heads in mice and man increases after exposure to most mutagens, carcinogens, and teratogens. Increases of the frequency of abnormally shaped sperm may indicate induced genetic damage. The usual methods for assessment of sperm defects, visual examination of morphological features of sperm mounted on microscope slides or estimation of sperm motility, are subjective. Individuals may score reproducibly, but substantial variability exists among technicians. Quantitative procedures are needed to provide objectivity and improve reproducibility. Automation would enhance speed, could provide standardization and should lead to improved archival libraries and data exchange and retrieval systems.

Advances in interpreting induced abnormalities in sperm require an improved means to measure sperm characteristics. This report reviews our application of several methods for automated, quantitative detection of shape changes, methods that are faster and more sensitive than conventional visual techniques. Variability of sperm deoxyribonucleic acid (DNA) content as a bioassay of genotoxic damage has been explored by us, and limitations of the bioassay are discussed. New flow cytometric techniques that could lead to sexing mammalian sperm have been developed during the course of this work and are described.

The goal of our studies is development of sensitive, noninvasive, statistically robust, analytical tools that can detect and quantify the frequency of altered sperm. These methods would be applicable in screening protocols and in programs that monitor effects of environmental contaminants. This approach is promising because the high rate of analysis allows measurement of large numbers of sperm so that small changes of frequencies might be detected.

\section{MORPHOLOGY}

\section{Quantitative Microscopy of Radiation-Induced Changes}

We have used quantitative microscopy to determine changes in sperm shape after varying doses of testicular $x$-irradiation (19). We employed $x$-irradiation because of the relatively uncomplicated dose-to-target determinations as compared to chemical mutagens. In this study five groups of three mice received single testicular doses of $x$-irradiation at dosages ranging from 0 to 120 rads. A random sample of 100 mature sperm per mouse was analyzed 5 wk later to quantitate abnormal sperm head morphology as a function of dosage. Cells were stained (9) with gallocyanin chrom alum (GCA) so that only the DNA in the sperm head was visible. The ACUity quantitative microscope system at Lawrence Livermore National Laboratory (19) was used to scan the sperm at a sampling density of 16 points per lineai micrometer and with 256 possible brightness levels per point. The contour of each cell was extracted by conventional thresholding techniques on high-contrast images. For each contour 10 shape features were computed to characterize the morphology of the cell.

With the control group's distribution of shape features determining the variability of a normal sperm population, 95\% limits on normal morphology were established. We found that as dose increased, surface area of cells became smaller and shape features indicated a significant trend toward circularity. With only the optimal 4 of the 10 shape features extracted from the sperm images, a doubling dose of approximately 39 rads was 
determined. That is, at 39 rads exposure the percentage of abnormal cells was twice the percentage in the control population. Comparison to a doubling dose of approximately 70 rads obtained from a concurrent conventional visual procedure may indicate a greater sensitivity of the image analysis method.

A companion study (11a) also suggests that quantitative methods can improve the sensitivity of measuring the effects of $x$ irradiation on sperm morphology. Quantitative measurements made on enlarged photographs of mouse sperm heads were related to radiation dose. Using a Mahalanobis distance statistic to measure distance in a multivariate space from a control group of measurements reduced the doubling dose from approximately 70 rad to 10 to 15 rad while keeping the percentage of abnormal sperm in control mice at $3 \%$, equal to the concurrent visual methoci.

\section{Influence of Chromosomal Translocations}

Certain chromosomal translocations (18) influence the morphology of sperm heads of mice, e.g., $T(14,15) 6 \mathrm{Ca}$. We used quantitative microscopy to determune whether we could distinguish mice with normal chromosomes from those carrying chromosomal rearrangements. We examined sperm from control mice and from mice heterozygous or homozygous for one of five chromosoma! translocations. For each translocation a set of 100 sperm cells was chosen randomly from a heterozygote-bred mouse and from a homozygote-bred mouse. One hundred control sperm cells wer $y$ selected randomly from each of two control mice. Cells were stained with GCA and the ACUity quantitative microscope system was used to scan the sperm cells at a spatial resolution and sampling density of four points per micrometer. Each cell contour was extracted by conventional thresholding techniques, and for each contour a variety of shape features were computed to characterize the morphology of that cell. Two features that reflect roundness, elliptical eccentricity and perimeter ${ }^{2}$ per area, yielded highly significant $(P<0.0001$ ) separation of the groups of mice. These preliminary studie's suggest that quantitative microscopy of sperm can be used to distinguish normal mice from certain translocation heterozygotes and translocation homozygotes.

\section{Measuring Head Shape by Flow Cytometry}

We also have applied slit-scan flow cytometry (SSFCM) to classification of mammalian sperm according to head shape (1). When analyzed for shape by SSFCM, fluorescently stained sperm are moved lengthwise at approximately $8 \mathrm{~m} / \mathrm{s}$ through an intense blue $(1 \mathrm{~W}, 488 \mathrm{~nm})$ bearn from an argon-ion laser that is shaped optically into a ribbon $2.5 \times 40 \mu$ in cross-section. The SSFCM measures the distribution of fluorescence in 50 to 100 narrow strips across each sperm head. When these intensities are time-ordered the composite fluorescence profile is a measure of sperm head morphology. Measurements are made on about $100 \mathrm{sperm} / \mathrm{s}$ and, thus, objective results with high statistical precision are obtained quickly.

Mouse, hamster, rabbit, and bull sperm were fixed with formalin and stained with an acriflavine-Feulgen procedure (5). An average fluorescence profile was generated for each species. Individual sperm were classified as morphologically normal or abnormal by comparison of their profiles to the average profiles by test of sum of squared differences. 


\section{Interspecies Comparisons}

The profile for each species has a characteristic shape (Figure 1). Sperm heads of roughly similar outline produce comparable fluorescence profiles. Mouse and hamster sperm have hooked heads and SSFCM of their sperm yields skew profiles; the paddle-shaped sperm of the bull and the rabbit produce more symmetric profiles. When the average Swiss Webster mouse sperm profile was used as a control and a threshold of fit was set to include $95 \%$ of mouse sperm profiles, then only $5 \%$ of hamrter and $0 \%$ of rabbit and bull sperm profiles fit within this threshold. Bull and rabbit sperm, which are difficult to differentiate visually are distinguished by this method. With the average rabbit sperm profile as the control, only $15 \%$ of bull sperm were within a threshold that included $95 \%$ of rabbit sperm.

\section{Effects of X-Irradiation on Mouse Sperm}

Caudal epididymal sperm were collected from $A K D 2 F_{1}$ mice that had received a single dose of $\mathrm{x}$-irradiation to their testicles 35 days earlier. Doses were $0,100,300,450$, 600 , or 900 rads. The SSFCM profiles were analyzed to determine the frequency of atypical sperm for each dose; the sperm also were scored visually for morphological abnormalities by traired, independent observers. The frequency of atypical sperm estimated by SSFCM correlated remarkably $(r=0.99)$ with frequencies of abnormally shaped sperm estimated by microscopic analysis (1). The sensitivity of the SSFCM assay was slightly lower than that of visual scoring, but in this study only 100 sperm were assayed by SSFCM per dose. In unpublished studies (6), between 500 and 1000 sperm per dose were anclyzed with SSFCM, and sensitivity of the SSFCM assay was equal to or better than the visual assay of sperm shape.

\section{HIGH RESOLUTION DNA CONTENT MEASUREMENTS}

The cytotoxicity of ionizing radiation has been studied by Hacker et al. (7) with murine spermatogenesis as an in vivo biologic dosimeter. Changes of the frequency distribution of cellular DNA content of whole testis preparations were analyzed by flow cytometry. A linear increase of the CV of DNA content of cells irradiated as spermatocytes, a dose-dependent arrest of differentiated spermatogonia, and an induction of diploid sperm were observed. However, a shoulder on the dose-effect curve of the irradiated spermatocytes limited the value of the method in the low-dose $(<100 \mathrm{rad})$ range. Evenson et al. (3) found that the DNA of misshapen sperm nuclei from unexposed bulls, mice, and humans has decreased resistance to thermal denaturtion. Many morphologically normal nuclei derived from subfertile donors were also abnormally sensitive to thermal denaturation of their DNA. Sperm DNA is readily denatured following exposure to chemical mutagens and carcinogens (Evenson, personal communication 19 July 1983). Thus, flow cytometry of sperm DNA content might provide a measure of damage in the genetic material of male germ cells following exposure of an individual to a mutagen, carcinogen, or teratogen. We have used several flow cytometric techniques to measure the relative DNA content of sperm (17).

\section{Mutagen Induced DNA Content Variability}

Accuracy of our measurements was established (17) by resolution of $X$ - and $Y$-chromosome-bearing sperm in normal mice (Figure $2 \mathrm{a}$ ) and those with the Cattanach 7 to $\mathrm{X}$ translocation (2) (Figure 2b) by two protocols. Staining sperm with 
4-6-diamidino-2-phenylindole (DAPI) and measuring fluorescence in an ICPC22 flow cytometer is one protocol; the other is measuring ethidium bromide mithramycin (EBMI) stained cells in the OFCM. Quantitative agreement of the response among these two protocols and another that use:s acriflavine-Feulgen stain measured with the OFCM reduces the probability that the response is a staining artifact.

Caudal epididymal mouse sperm collected 35 days after acute localized exposure of testes to $x$ rays show dose-dependent increases of the $C V$ of fluorescence distributions of DNA conterit (Figure 3). Comparison of dose response curves obtained with protocols that overcome optical and cytochemical difficulties in different ways leads to the conclusion that the response is due to $x$ ray induced DNA content variability (16).

In the range between 0 and 600 rads the dose dependence of the square of $\mathrm{CV}$ of the DNA content variability, $C V_{D}^{2}$, is described by $C V_{D}^{2}=B x+C x^{2}$, with $0 \leq B \leq$ $0.23 \times 10^{-2}$ and $C=(0.44 \pm 0.06) \times 10^{-4}$. The dose $x$ is measured in rads, and $C V_{D}$ is expressed in percent (16). Computer modeling of the shapes of the fluorescence distributions shows that at 600 rads 30 to $40 \%$ of the sper m have abnormal DNA content. Sorre have deviations as large as two whole chromosomes, but it is not clear whether they are due to whole chromosome nondisjunction, a finer fragmentation of the genome, or an effect of the irradiation on DNA-stain stoichiometry.

Aged mice, 27 to 30 mo old, show no increased response relative to 3 mo old controls, and the $C V$ for unexposed animals is independent of age. Benzo(a)pyrene (B(a;P) and mitomycin $C$ (MMC) cause abnormalities of sperm shape but no measurable variability of DNA content. This can be interpreted as a control for morphologic effects on the flow measurement of DNA content. Because the $x$ ray dose response has a small slope at low doses and $B(a) P$ and $M M C$ cause no detectable response in DNA content, the sensitivity of this technique is low, and its utility for detecting mutagen exposure will be limited to agents that produce aneuploidy in sperm. Using another species with fewer chromosomes than the mouse might help optimize detection of exposure-induced errors in DNA content.

\section{$\mathrm{X}$ - and $\mathrm{Y}$-Chromosome-Bearing Sperm}

The DNA content of spermatids from chromosomally normal mice ( 11 ) and from mice carrying Cattanach's translocation (10) has been measured by flow cytometry. These studies, which report two peaks essentially analogous to those in our study (Figure 2), help substantiate our belief that the two peaks in our study (17) represent $X$ - and $\mathrm{Y}$-chromosome-bearing sperm. The ability to obtain excellent resolution of the two peaks is useful for other biological applications. For exarnple, using sperm selection methods to influence the sex ratio of agriculturally important animals would have profound genetic importance and marked economic impact. We (4) have quantified $X$ - and $Y$-chromosome-bearing sperm from ram, rabbit, boar, and bull semen using a slight modification of the method in the mouse studies. Although we have yet to resolve the $X$ and $Y$ subpopulations of human sperm, Otto et al. (14) have demonstrated such subpopulations and found a DNA difference between them of $3.4 \%$. Our measurements of cockerel sperm predictably produced one narrow peak as the cockerel is the homogametic sex.

Flow cytometry, when used for $X-Y$ sperm discrimination, exploits the only established difference between $X$ - and $Y$-sperm; i.e., the quantity of DNA in the sex chromosome. The small differences of $X-Y$ peak separations seem to represent the actual DNA content difference of the chromosomes but could be caused by more subtle effects, 
e.g., differences of base composition of the DNA. Even small differences of base composition of the sex chromosomes could be magnified by the preference of DAPI for adenine-thymine base pairs. Nonetheless, -.lthough the observed fluorescence would not be proportional to the DNA content of the sperm, the two peaks still would represent $X$ and $Y$ sperm.

Analyses of bimodal frequency distributions by fitting two Gaussian distributions to the data showed that fluorescence intensity of the peaks differed by $3.9,3.7,4.1$, and $3.9 \%$ for bulls, boars, rams, and rabbits (4). In four replicate analyses of semen from 25 bulls representing 5 breeds, the average area for the $Y$-peaks was $50 \pm 0.5 \%$, as typified in Figure 4. The $X-Y$ peak differences did not vary within breeds but varied among breeds. Sperm from Jersey bulls had larger $X-Y$ peak differences $(P<0.001)$ than sperm from Holstein, Hereford, and Angus bulls; sperm from Brahman bulls had smaller $X-Y$ differences $(P<0.004)$.

This work demonstrates that flow cytometry can assess the relative DNA content of sperm from domestic animals (data not presented here) and determine the natural ratio of $X$ - to Y-chromosome-bearing sperm in fresh semen of at least five species and cryopreserved bull and boar semen. Moreover, it suggests that the ability to determine relative populations of $\mathrm{X}$ - and $\mathrm{Y}$-chromosome-bearing sperm in a semen sample would provide a quick, accurate method to determine the success of a proported sperm selection technique. The practical ability to influence the sex ratio of progeny would have profound impacts on the livestock inciustry. It could result also in considerable conservation of feed, fertilizer, and other energy-expensive activities of modern agriculture. Not only is flow cytometry useful for assessment of enrichment but it also may be used to develop new methods of separating $X$ - and $Y$-sperm and to provide quality control for enrichment techniques that reach commercial application.

\section{Separation of Heterogametic Sperm}

Development of semen-based sex selection techniques has been impeded by the difficulty of identifying differences that might serve as a basis for enrichment or preferential inactivaticn of $\mathrm{X}$ - or Y-sperm. Appropriately adapted flow sorting instrumentation can be used to separate sperm based on DNA content. These sperm could be used to search for phenotypic differences that might be exploited for bulk separation of viable cells. However, current staining techniques (17) adequate to resolve a 3 to $4 \%$ difference in mean DNA content require decondensation of the highly compact sperm nucleus with proteolytic enzymes, substantially altering many biochemical components and generally distupting sperm structure. The larger the difference in DNA content between the sex-determining sperm populations, the more biochemically conservative a staining protocol can be and still resolve the populations. For the vole, Microtus oregoni, this difference is about $9 \%$, more than double that of most mammals (12).

M. oregoni is unusual in that it is a gonosomic mosaic (13); the gonadal and omatic cells have different chromosomal constitutions. Male somatic cells are $X Y$, but spermatogonia are OY. Thus, one of the sperm populations contains the $Y$ chromosome and the other, called "O", contains no sex chromosome. In this animal only $Y$-linked genes are candidates for coding for markers that differentiate the two sperm classes. This may not be different from other mammals as there is evidence that the $X$ chromsome normally is inactivated during spermatogenesis (8). 
In what we believe to be the first verified sperm separation in a mammal (15), caudal epididymidal sperm from trapped $M$. oregoni were dispersed for flow sorting, stained with DAPI, and sorted after preparation according to three protocols: 1) Papain and dithioerythritol treatment to decondense the chromatin (17). Sperm tails and other cytoplasmic structures also are removed. This procedure yields good DNA content resolution (Figure 5). 2) Sonication followed by fixation in $80 \%$ ethanol. This also removes tails, but staining precision is considerably reduced. 3) Fixation of intact cells in $10 \%$ phosphate buffered formalin. Sperm tails are not removed and resolution is reduced further. Sorting rates in these experiments were on the order of $30 \mathrm{cells} / \mathrm{s}$ for each fraction.

Purity of the sorted fractions was determined by restaining the sperm according to protocol 1, measuring the sperm of each fraction in the ICP22, and computer fitting a pair of normal distributions to the resulting data. The relative areas of the two fitted curves give the relative $Y$ and $O$ populations in each fraction. Figure 6a shows measurement of the $O$ fraction sorted from the sonicated ethanol fixed cells; the $Y$ fraction is shown in 6b. Their photographic superposition, which should be compared to Figure 5, . shown in Figure 6c. Analysis shows 95, 87, and $82 \%$ purity of $O$ fractions for protocols 1,2 , and 3. Purities of $Y$ fractions were 72, 83, and $80 \%$.

Two problems currently prevent insemination of sorted sperm: low sorting rates and lytic staining techniques. Even if vital staining techniques are developed and the sorting rate is increased to about $10^{3}$ sperm/s, use of sorted sperm for AI will not be widespread because several million cells per insemination are required. Application to in vitro fertilization, where the required number of sperm is significantly lower, is more probable.

For the immediate future, flow sorting of $M$. oregoni sperm offers the possibility of directly addressing the question of haploid expression of sex chromosome genes. A genetic marker might permit bulk separation of viable sperm, perhaps with an antibody to bind one population to a column while allowing the other to pass through. If there is a Y-specific $M_{\text {. }}$ oregoni marker that is conserved across species, it would have general application to mammalian sex selection. In the absence of a common $Y$-specific marker, extension to other species will require sorting of biochemically preserved sperm differing in DNA content by 3 to $4 \%$.

\section{CONCLUDING REMARKS}

Male germ cells respond dramatically to a variety of insults and are important reproductive dosimeters. Semen analyses are very useful in studies on the effects of drugs, chemicals, and environmental hazards on testicular function, male fertility and heritable germinal mutations. The accessability of male cells makes them well suited for analytical cytology. We might automate the process of determining sperm morphology but should not do so solely for increased speed. Rather, richer tangible benefits will derive from cytometric evaluation through increased sensitivity, reduced subjectivity, standardization between investigators and laboratories, enhanced archival systems, and the benefits of easily exchanged standardized data. Inroads on the standardization of assays for motility and functional integrity are being made. Flow cytometric analysis of total DNA content of individual sperm is an insensitive means to detect exposure to reproductive toxins because of the small size and low frequency of the DNA content errors. Flow cytometry can be applied to determine the proportions of $X$ - and $Y$-sperm in semen samples. 


\section{REFERENCES}

1. Benaron, D.A., J.W. Gray, B.L. Gledhill, S. Lake, A.J. Wyrobek \& I.T. Young. 1982. Quantification of mammalian sperm morphology by slit-scan flow cytometry. Cytometry 2: 344 .

2. Cattanach, B.M. 1961. $\bar{A}$ chemically induced variegated-type position effect in the mouse. Z. Vererbungsl 92: 165.

3. Evenson, D.P., Z. Darzynkiewicz \& M.R. Melamed. 1980. Relation of mammalian sperm chromatin heterogeneity to fertility. Science 210: 1131.

4. Garner, D.L., B.L. Gledhill, D. Pinkel, S. Lake, D. Stephenson, M.A. Van Dilla \& L.A. Johnson. 1983. Quantification of the $X$ - and $Y$-chromosome- bearing spermatozoa of domestic animals. Biol. Reprod. 28: 312.

5. Gledhill, B.L., S. Lake, L.L. Steinmetz, J.W. Gray, J.R. Crawford, P.N. Dean \& M.A. Van Dilla. 1976. Flow microfluorometric analysis of sperm DNA content: effect of cell shape on the fluorescence distribution. J. Cell Physiol. 87: 367.

6. Gray , J.W., J.D. Halamka, B.L. Gledhill, S. Lake, L.A. Gordon \& A.J. Wyrobek. 1983. Cytometry, in press.

7. Hacker, U., J. Schumann, W. Göhde \& K. Müller. 1981. Mammalian spermatogenesis as a biologic dosimeter for radiation. Acta Radiol. Cncology 20: 279.

8. Lifschytz, E.. 1972. X-chromosome inactivation: an essential feature of normal spermiogenesis in male heterogametic organisms. In Edinburgh Symposium on the Genetics of the Spermatozoon. R.A. Beatty \& S. Glueckshohn-Waelsch, Eds. p. 223. University of Edinburgh Press, Edinburgh, Scotland.

9. Mayall, B. 1969. Deoxyribonucleic acid cytomorphometry of stained human leukocytes: I. Differences among cell types. J. Histochem. Cytochem. 17: 249.

10. Meistrich, M.L., W. Göhde, R.A. White \& J.L. Longtin. 1979. "Cytogenetic" studies of mice carrying Cattanach's translocation by flow cytometry. Chromosoma 74: 141 .

11. Meistrich, M.L.., W. Göhde, R.A. White \& J. Schumann. 1978. R esolution of $X$ and Y spermatids by pulse cytophotometry. Nature (London) 274: 821 .

Ila. Moore, II, D.H., D.E. Bennett, D. Kranzler \& A.J. Wyrobek. 1982. Quantitative methods of measuring the sensitivity of the mouse sperm morphology assay. Anal. Quant. Cytol. 4: 199.

12. Moruzzi, J.F. 1979. Selelcting a mammalian species for the separation of $X-$ ano Y-chromosome-bearing spermatozoa. J. Reprod. Fertil. 57: 319.

13. Ohno, S., J. Jainchill \& C. Stenius. 1963. The creeping vole as a gonosomic mosaic. The OY/XY construmiun in the mole. Cytogenetics 2: 232.

14. Otto, F.J., J. Hacker, J. Zante, J. Schumann, W. Göhde \& M.L. Meistrich. 1979. Flow cytometry of human spermatozoa. Histochemistry 61: 249.

14a. Pinkel, D. 1983. Dose effects in sperm based on cytometric detection of changes in morphology and DNA content. In Biological Dosimetry: Cytometric Approaches to Mammalian Systems. W.G. Eisert \& M.L. Mendelsohn, Eds., in press.

15. Pinkel, D., B.L. Gledhill, S. Lake, D. Stephenson \& M.A. Van Dilla. 1982a. Sex preselection in mammals? Separation of sperm bearing $Y$ and "O" chromosomes in the vole Microtus oregoni. Science, 218: 904.

16. Pinkel, D., B.L. Gledhill, M.A. Van Dilla, S. Lake \& A.J. Wyrobek. 1983. Radiation induced DNA content variability in mouse sperm. Radiat. Res., 95: 550.

17. Pinkel, D., S. Lake, B.L. Gledhill, M.A. Van Dilla, D. Stephenson \& G. Watchmaker. 1982. High resolution DNA content measurements of mammalian sperm. Cytometry 3 : 1. 
18. Wyrobek, A.J., J.A. Heddle \& W.R. Bruce. 1975. Chromosomal abnormalities and morphology of mouse sperm heads. Can. J. Geriet. Cytul. 17: 675.

19. Young, I.T., B.L. Gledhill, S. Lake \& A.J. Wyrobek. 1982. Quantitative analysis of radiation-induced changes in sperm morphology. Anal. Quant. Cytol. 4: 207. 


\section{FIGURE CAPTIONS}

Figure 1. Average slit-scan flow cytometric profiles for sperm from four marmals. The soild line is a sample average; the dotted lines represent I SD from the average. Sperm from each animal yield an average profile with a distinct length and shape (1).

Figure 2. The DNA content of $Y$-sperm is measured accurately. Fluorescerice distributions of EBMI stained sperm from normal mice (a) and those with the rattanach 7 to $X$ translocatior. (b). The separation of the peaks is determined by fitting a pair of normal distributions to the data. The separations agree with the differences expected from measurements of the individual chromosomes (17).

Figure 3. The observed $x$-ray dose response is the same for three measurement techniques. The square of the coefficient of variation of the fluorescence distribution, $C V_{D}$, increases with raoiation for the three protocols. Each symbol represents an independent determination. The solid line is the least squares fit of a second order polynomial (second equation) to the data (14a).

Figure 4. Resolution of bull $X$ - and $Y$-sperm populations. For computer analysis the distribution obtained from flow cytometric measurement was truncated to the channels of fluorescence intensity shown and fitted with a pair of Gaussian distributions. Each of the two distributions is represented by small dots (...) and thei sum by the solid line $(\longrightarrow$. The actual number of sperm per channel are shown as large dots $(\cdot)$. The only restriction placed on the computer fit was that the coefficients of variation be identical. There were $51 \%$ of the sperm in the $Y$ peak (lower intensity) and $49 \%$ in the $X$ peak. The difference in modal fluoresrence intensity of the two peaks was $3.94 \%$ $(14 a)$.

Figure 5. The "O" and $Y$ sperm populations are ciearly resolved in $M$. oregoni and the $9.1 \%$ difference in modal fluorescence intensity of the two peaks (14a) corresponds closely to the $8.8 \%$ expected based on length of chromosome measurements made by Moruzzi (12).

Figure 6. Verification of sorting purity of $M$. oregoni sperm. Sperm prepared with protocol 2 were sorted into two fractions. After sorting, the putatively enriched fractions were restained using protocol 1 and analyzed in the ICP22. Analysis of the $\mathrm{O}$ - and $\mathrm{Y}$-fractions are shown in (a) and (b) respectively. The photographic superposition (c) of the peaks should be compared to 8 (14a). 


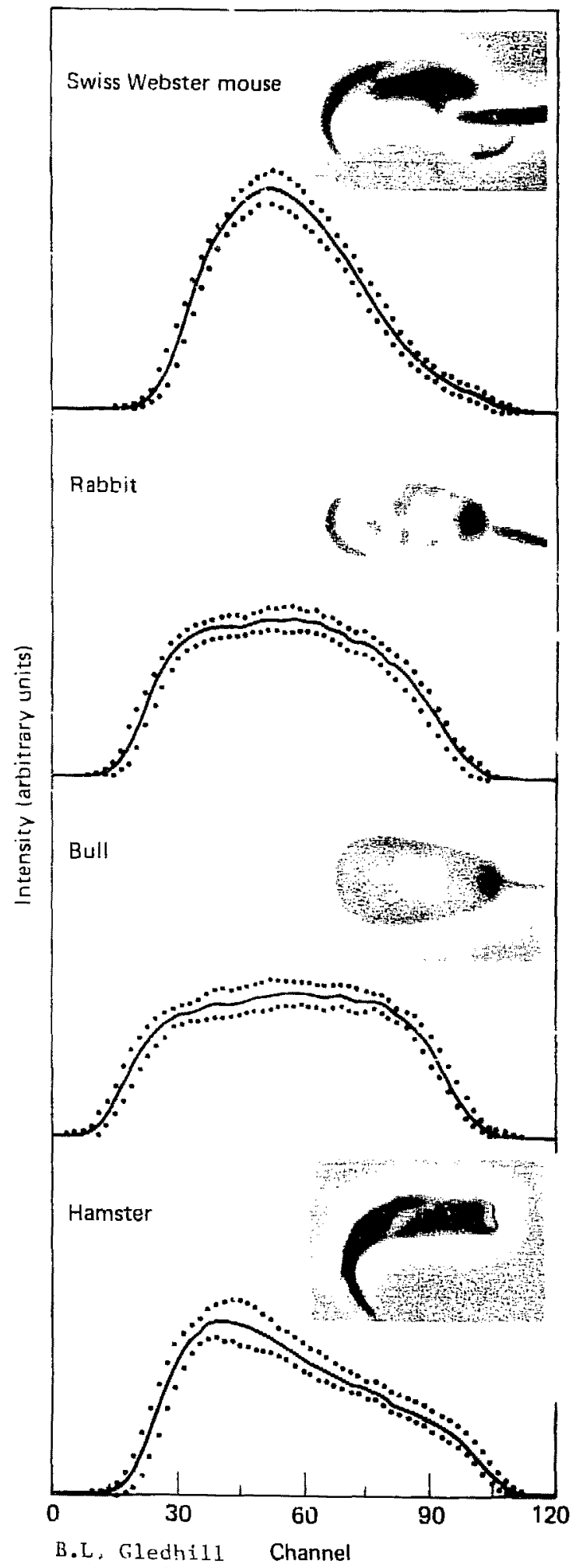

Fig. 1 

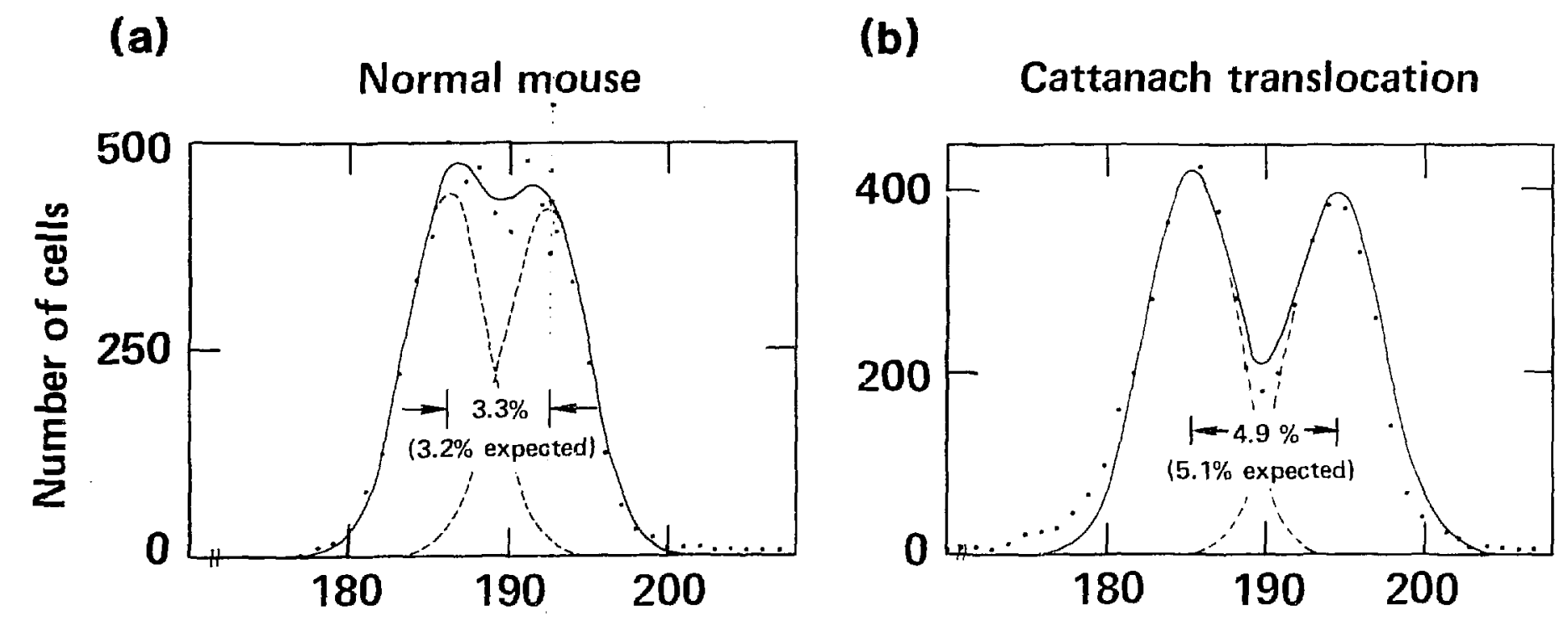

Fluorescence intensity 


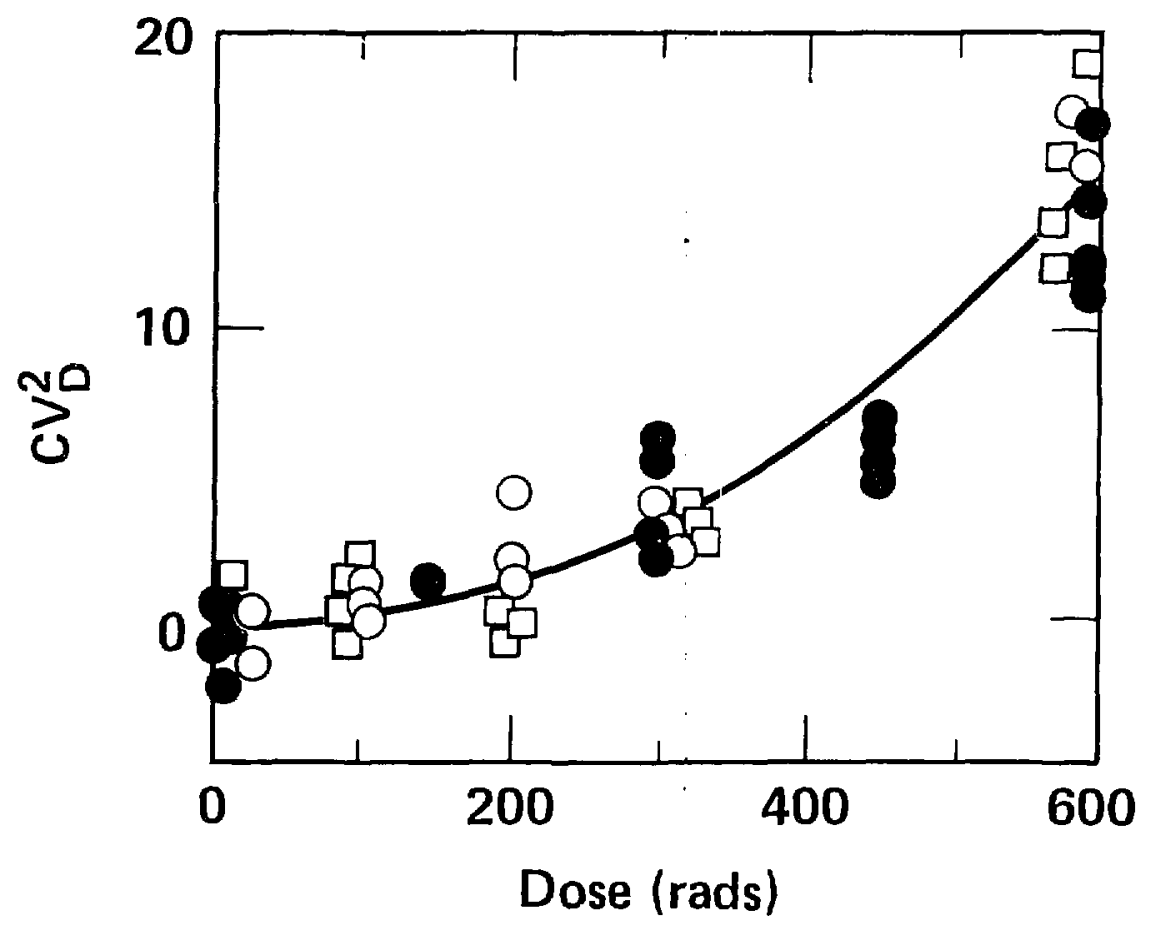

- Acriflavine Feulgen-OFCM

ㅁ EBMI-OFCIM

O DAPI-ICP22

$$
\mathrm{CV}^{2}=\mathrm{CV}_{0}^{2}+\mathrm{CV}_{\mathrm{D}}^{2}(\mathrm{x})
$$$$
\mathrm{CV}_{\mathrm{D}}^{2}(\mathrm{x})=\mathrm{Bx}+\mathrm{Cx}^{2}
$$$$
B \leqslant 0.23 \times 10^{-2}
$$$$
C=(0.44 \pm 0.06) \times 10^{-4}
$$ 


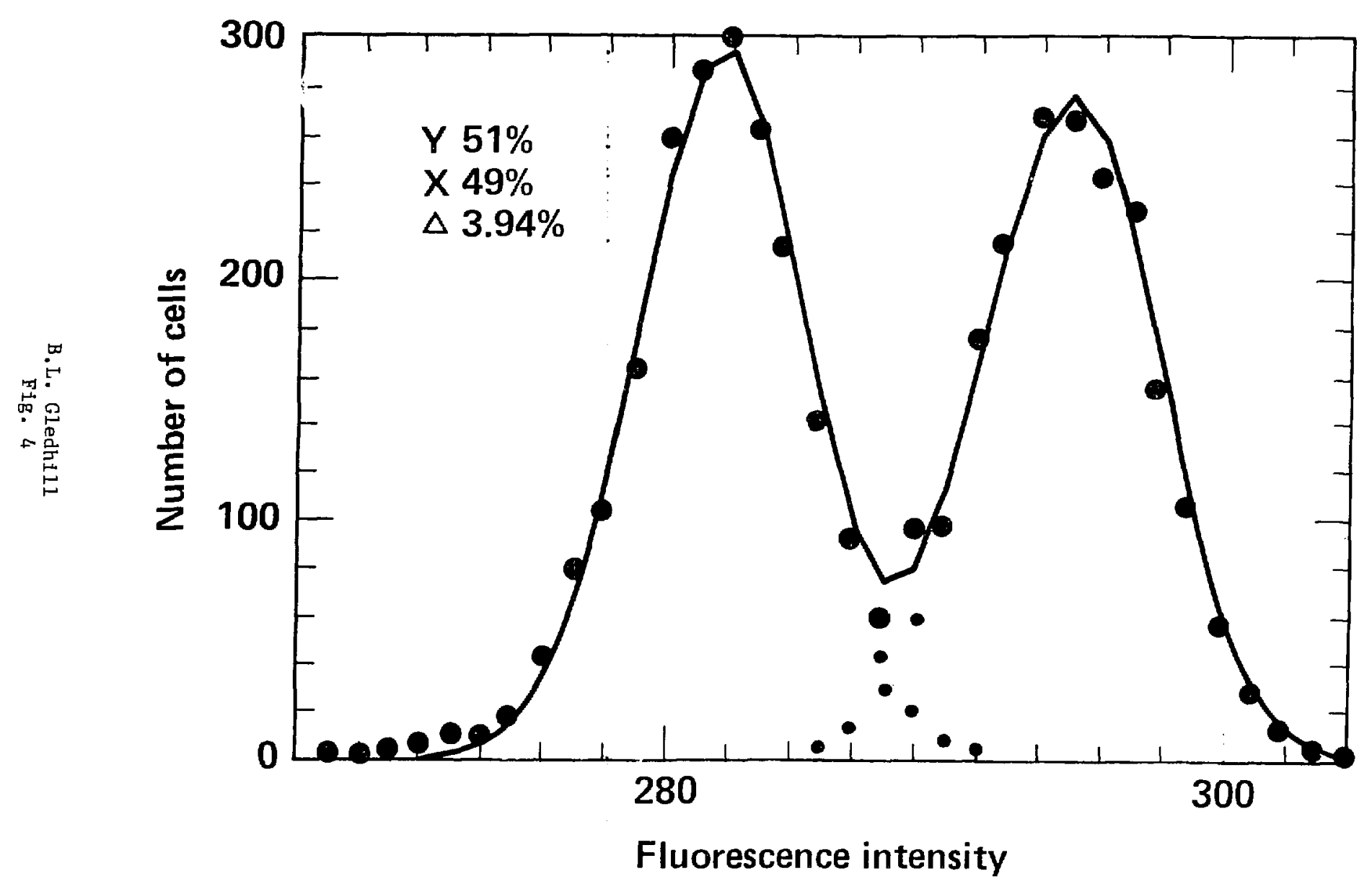




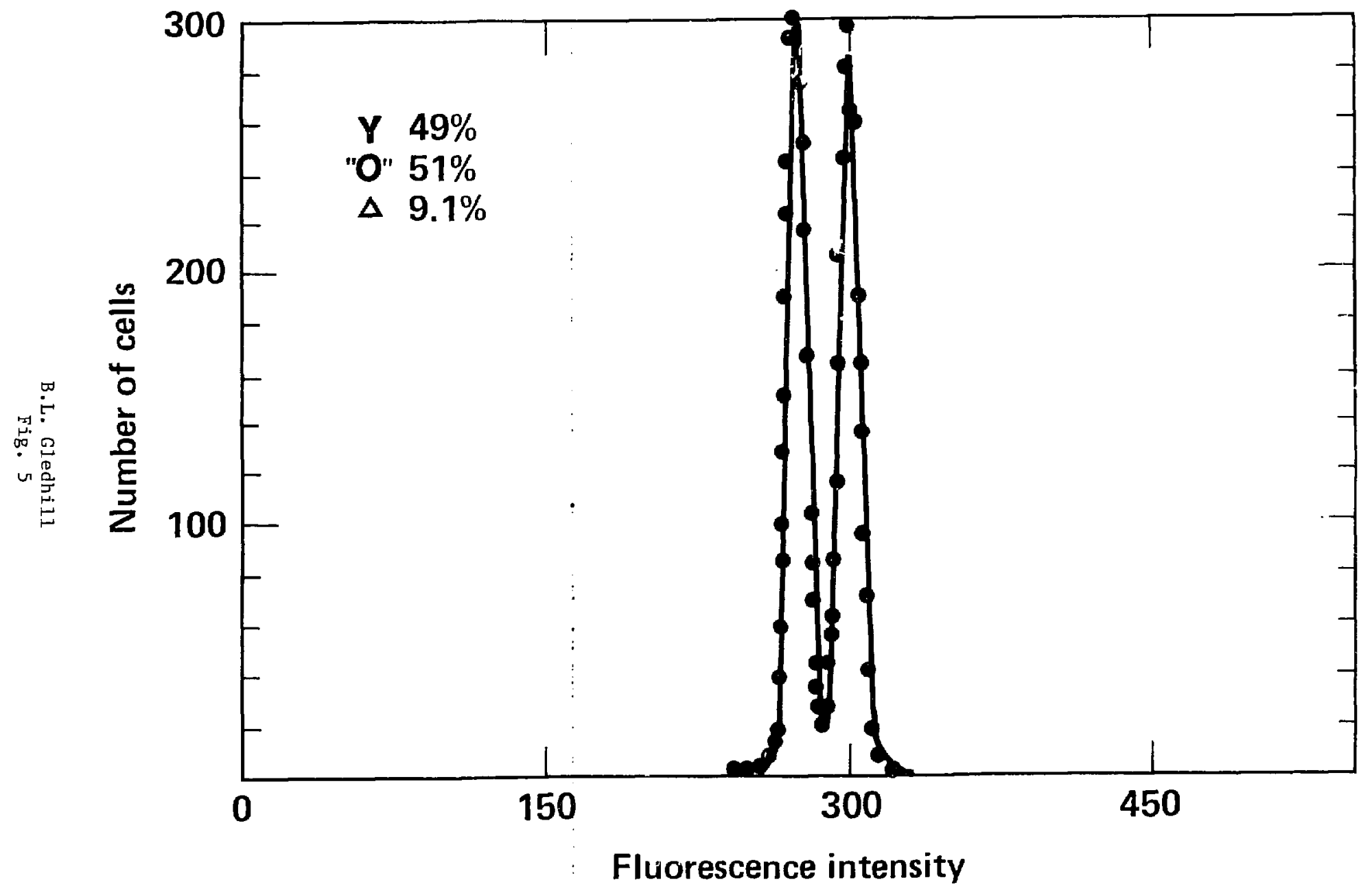




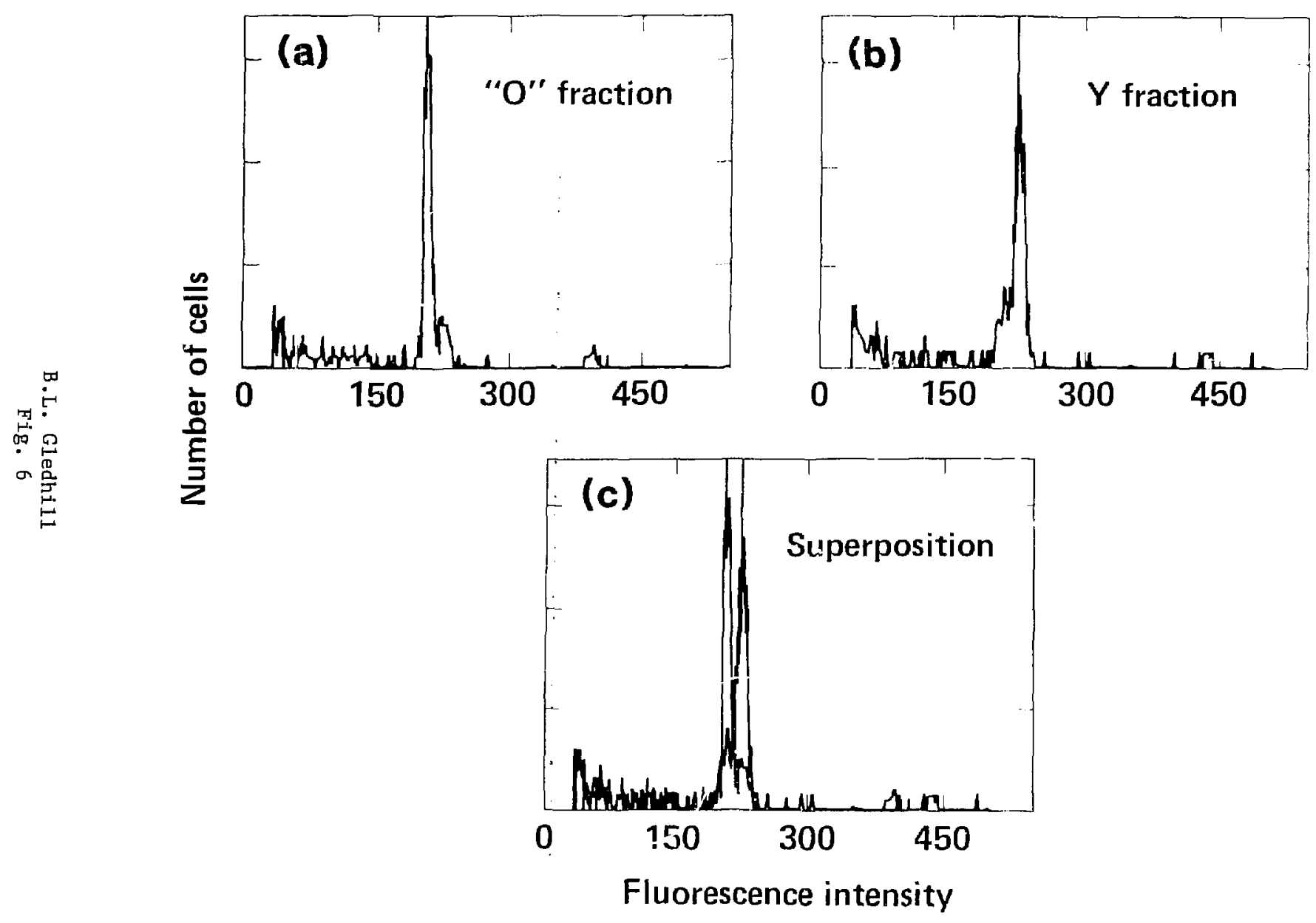




\section{DISCLAIMER}

This document was prepared as an account of work sponsored by an agency of the United States Government. Neither the United States Sovernmeiri nor the University of Califomia nor any of their employees, makes any warranty, express or implied, or assumes any legal liability or responsibjlity for the accuracy, completeness, or usefulniess of any information, apparatus, product, or process disclosed, or represents that its use would not infringe privately owned rights. Reference herein to any specific commercial prodacts, process, or service by trade name, trademarh, manufacturer, or ofherwise, does not necessarily cunstitute or imply its endorsement, recommendation, or favoring by the United States Government or the University of Califomia. The views and opinions of authors expressed berein do nol necessarily state ar reflect those of the United Stales Government thereof, and shall not be used for advertising or product endorsement purposes. 